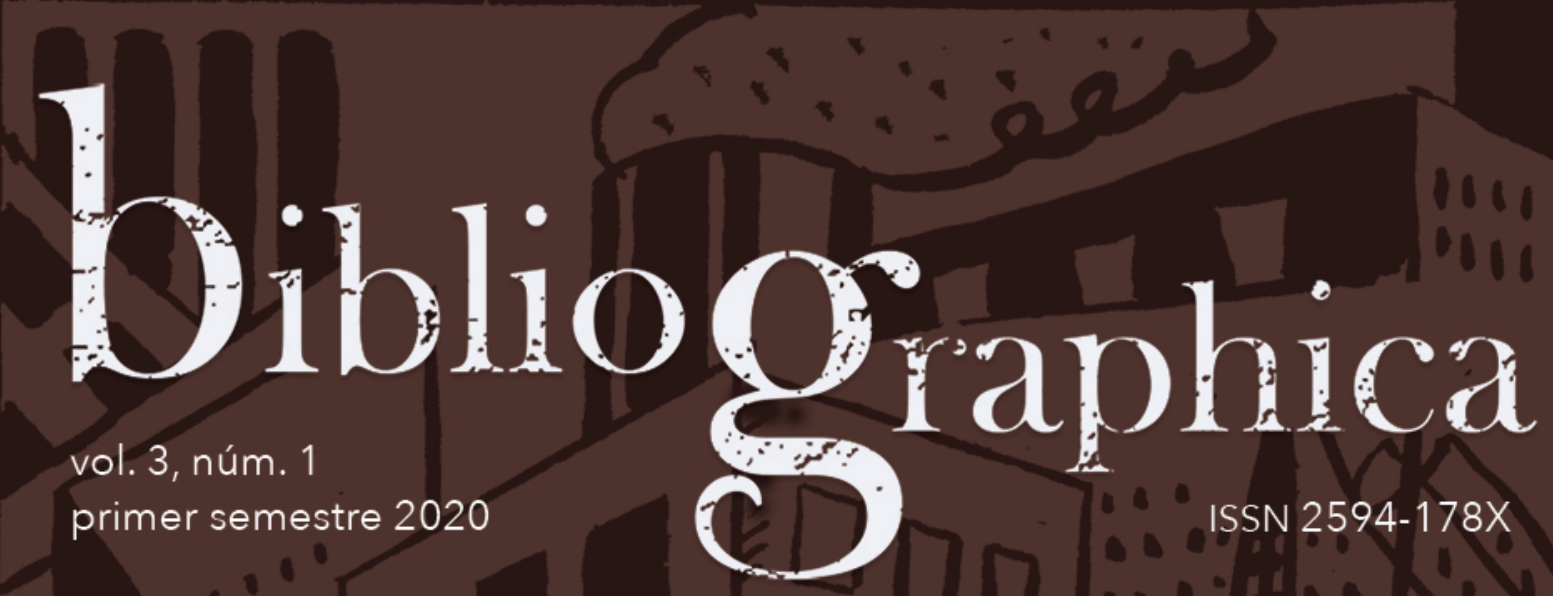




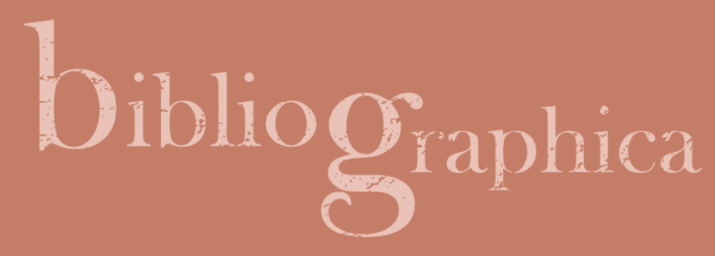

\section{El cuento mexicano contemporáneo: cualidades genéricas y su implicación editorial}

The Contemporary Mexican Short Story:

Generic Qualities and Editorial Implications

Laura Elisa Vizcaíno Mosqueda

vizcainomosqueda@hotmail.com

Universidad Nacional Autónoma de México

Instituto de Investigaciones Bibliográficas

Recepción: 02.10.2019 / Aceptación: 05.11.2019

DOI: https://doi.org/10.22201/iib.2594178xe.2020.1.63 
Resumen El cuento suele relacionarse con la novela, el ensayo y a veces con la poesía, debido a que no hay límites estrictos en cuanto a la extensión y a que la prosa puede mezclarse con otros tipos de escritura. Sin la intención de definir géneros literarios, este artículo busca asentar que la hibridez del cuento incide en sus formas de publicación y, por tanto, en su trayectoria editorial. En consecuencia, será necesario revisar sus aspectos estructurales, las perspectivas del contexto cultural desde donde el cuento es creado, la importancia de las publicaciones que agrupan varios textos -como las revistas y antologías-, el aporte de las bibliografías sobre el cuento y algunas colecciones editoriales que han apostado por el género.

Palabras clave

Abstract

Keywords
Cuento mexicano; bibliografías del cuento; trayectoria editorial; empresas editoriales; recepción del cuento.

Short stories are often related with novels, essays and sometimes even with poetry, this is due to the fact that there aren't strict limits in terms of extension and that prose can be mixed with other types of writing. Without the intention of defining what literary genres are, this paper seeks to sustain that hybridization of short stories affects its publications forms and, by extension, its editorial trajectory. As a result, it would be necessary to review its structural aspects, perspectives of the cultural context in which the short story is created, the importance of publications that gather several short stories -such as magazines and anthologies-, the contribution of short story bibliographies and some editorial collections that have opted for this gender.

Mexican short story; short story bibliographies; editorial trajectory; publishing companies; short story reception. 


\section{Introducción}

El cuento, al igual que otras formas de escritura milenaria, puede estudiarse desde muchas aristas; sobre todo ha sido analizado desde las líneas literarias, históricas, genéricas y, en menor medida, en cuanto a sus posibilidades de publicación, que no dejan de estar emparentadas con las tres anteriores. Observar el cuento desde su trayectoria editorial aporta a la totalidad de los estudios de este género; las preguntas dónde, cómo y cuánto se publica refieren a los aspectos formales, productivos y de recepción de esta forma literaria. El interés por responder estas incógnitas no sólo radica en la intención de sumar a los estudios editoriales específicos del cuento, sino también en la curiosidad por comprender la relación entre las cualidades genéricas y sus modos de difusión.

Para encontrar las respuestas es necesario atender las vertientes de análisis mencionadas, así como una revisión de los caminos que ha seguido el cuento para ser publicado. Aunque sea necesario mencionar tiempos remotos de este género y su difusión en revistas, el presente artículo busca puntualizar las formas de publicación del cuento mexicano contemporáneo (finales del siglo XX hasta la fecha), específicamente en el soporte del libro impreso.

Como una posible hipótesis, la estructura breve de esta forma literaria abre la posibilidad a más de un modo de publicación. Sin embargo, otra pregunta a responder sería: una vez que el cuento encuentra su soporte, ¿qué tan conveniente es hacer libros de cuento? Para responder será necesario identificar el contraste entre el libro impreso y las publicaciones periódicas, las opciones de las antologías de un solo autor o en compendios de varios autores y las biblio-

grafías dedicadas al cuento, además de hacer un brevísimo análisis del tipo de editoriales que apuestan por este género y las colecciones que lo contienen.

\section{Aspectos genéricos, estructurales y culturales}

Para entender el cuento desde el punto de vista editorial hay que hacer un balance con el peso de la novela. Esto no quiere decir que el género extenso sea opuesto al otro por cuestión de tamaño, sino más bien que en las líneas divisorias de ambos géneros se encuentran pistas para comprender los modos de publicación. Teoría y técnica del cuento, del argentino Enrique Anderson Imbert, plantea una distinción genérica a partir de la cual es posible rastrear los inicios del cuento: "en Don Quijote el episodio de 'El curioso impertinente' está presentado como novela porque se trata de la lectura de un manuscrito hallado en 
una maleta pero en cambio se habla de 'el cuento de la pastora Marcel' porque es un cabrero quien lo narra en viva voz". . Con base en este ejemplo, Anderson Imbert deduce que la diferencia entre ambos géneros no es una cuestión de dimensiones, sino de actitud. El cuento está emparentado con la narración oral y popular, mientras que la novela lo está con la materialidad libresca.

Sin embargo, no todo acto de oralidad deriva exclusivamente en el cuento. Al comienzo del estudio de la parodia, Gérard Genette recupera la importancia de los rapsodas en la época antigua, quienes se encargaban de contar al pueblo grandes poemas como La Odisea; en su labor comprendieron que tergiversar en cierta medida la historia original provocaba la atención del público, por tanto, incluían alguna burla o cambio de tono que rompiera con la solemnidad. ${ }^{2}$ En consecuencia, la oralidad funciona acertadamente con extensiones largas o extensas, pero su efecto puede ser más certero con una breve durabilidad, o bien con tonos lúdicos.

Respecto al cuento, "en sus orígenes históricos, fue una diversión dentro de una conversación; y la diversión consistía en sorprender al oyente con un repentino excursus en el curso normal de la vida". ${ }^{3}$ Hasta la fecha, el término "cuento" nunca ha tenido una designación única y puede utilizarse, como ocurría en el Renacimiento, para hablar de chistes, refranes o casos curiosos. Asimismo, se hibrida con otros géneros como la prosa poética, la narración metafórica o el ensayo narrativo. Por ejemplo, en El amor que destruye lo que inventa. Historias de la historia de Vicente Quirarte, Frédéric-Yves Jeannet menciona en el prólogo la peculiaridad mestiza del libro: "Los cuentos pueden oscilar entre narración y ensayo, y los ensayos a menudo se convierten en poemas o relatos [...]. Aunque se hagan pasar por cuentos, algunos textos rebasan los ámbitos y límites del género". Ésta es tan sólo una muestra de la colindancia genérica, pero en general el cuento se resiste a los cajones estrictos y por ello, como se verá a continuación, son habituales las publicaciones heterogéneas, es decir, las que agrupan múltiples trabajos; así es el caso de las revistas, las antologías, o en colecciones editoriales abiertas a todo tipo de narrativa, no solamente de la que nos ocupa.

\footnotetext{
${ }_{1}^{1}$ Enrique Anderson Imbert, Teoría y técnica del cuento (Buenos Aires: Ariel, 1992), 16.

${ }^{2}$ Gérard Genette, Palimpsestos (Madrid: Taurus, 1989), 23.

${ }^{3}$ Anderson Imbert, Teoría y técnica, 23.

${ }^{4}$ Frédéric-Yves Jeannet, prólogo a El amor que destruye lo que inventa. Historias de la historia, de Vicente Quirarte (México: Conaculta, 1995), 9.
} 
La razón de mencionar la importancia de los géneros consiste en preparar el terreno respecto a algunas miradas editoriales y su postura frente al objeto de estudio. A inicios del siglo XX, Pedro Henríquez Ureña consignó: "No tenemos ( iestúpidos!) casas editoriales que nos hagan vivir literariamente. Sin casas editoriales no se pueden escribir novelas. Y las novelas son el sesenta por ciento de la literatura moderna". ${ }^{5}$ Independientemente del porcentaje mayoritario que el autor otorga a la novela, con el paso del tiempo, y desde la perspectiva editorial, no se ha modificado la consideración respecto al éxito del género extenso.

Desde un punto de vista más reciente, el fundador de las editoriales Siruela y Atlanta, Jacobo Siruela, afirma: "los éxitos están en las grandes novelas y en los ensayos, curiosamente. Nuestros libros de cuento, tanto de Tsutsui y alguno más, nos han ido discretamente bien en ventas". ${ }^{\circ}$ ¿Cuáles podrían ser las razones por las que el cuento no vende de la misma manera que la novela? Según Andre Schiffrin "se publica el libro que cuente con un prepúblico y garantice los ingresos necesarios para el mantenimiento de la industria; por lo tanto, se admiten autores conocidos y temas de moda, mientras que los nuevos autores, con aportaciones originales y trascendentes culturalmente son relegados".' Bajo esta consideración habría que suponer que el cuento no está de moda.

En la primera mitad del siglo XX, Julio Torri hacía una comparación irremediable entre el cuento y su pariente cercano, la novela, que entonces podría indicar una diferencia en cuanto a las preferencias del público:

El cuento corresponde antes que todo a lectores u oyentes más ingenuos y pueriles, que sólo buscan en él un entretenimiento pasajero o la fácil ejemplificación de ideas morales sencillas. El cuento corresponde más bien a una etapa en el desenvolvimiento cultural de una nación. La novela corta en cambio va destinada a una clase social especializada en achaque de letras y que sabrá deleitarse con los incidentes dramáticos del relato, con la pintura del color local

\footnotetext{
${ }^{5}$ Citado en Freja Cervantes y Pedro Valero, La colección Cvltvra y los fundamentos de la edición mexicana moderna (1916-1923) (México: Juan Pablos / Secretaría de Cultura, 2016), 27.

6 Jacobo Siruela, "Imaginación, brevedad y memoria", Confabulario, suplemento de El Universal, entrevista por J. C. Guinto, acceso 9 de octubre de 2019, http://confabulario. eluniversal.com.mx/jacobo-siruela-imaginacion-brevedad-y-memoria/.

${ }^{7}$ Citado en Hugo Figueroa y Samira García, "Vivencia y convivencia en el universo editorial y de la información", en Recursos bibliográficos y de información, coord. de Hugo Figueroa y César Ramírez (México: UNAM, FFyL, 2006), 110.
} 
[...]. En ciertas épocas primitivas de la literatura de un país no ha habido sino cuentos, en tanto que la novela corta aparece en los periodos más adelantados, durante los cuales subsiste y se desarrolla el cuento. ${ }^{8}$

Si las afirmaciones de Torri son certeras, significaría entonces que no hay público para el cuento, debido a una proliferación de lectores especialistas no ingenuos. Sin embargo, su postura está basada en las convenciones de hace más de 50 años. En cambio, en la primera década del siglo XXI, Rosa Beltrán comenta cómo la publicación del cuento está destinada a "la muerte súbita", dado que para algunas editoriales esta forma literaria requiere de cierta competencia y de una voz distinta a la del mercado. ${ }^{9}$ Contrario a las opiniones del escritor coahuilense, el público del cuento es más exclusivo y por esta razón no tendrá tanta demanda.

En las disyuntivas se agrega una más, de Fernando Escalante Gonzalbo:

La mayor parte de los posibles compradores de libros son gente que no lee casi nunca, gente a la que le resulta penoso leer un libro de mínima dificultad, y que no está familiarizada con el conjunto de referencias ni con el diálogo del que forman parte los escritos estética o conceptualmente más ambiciosos. Eso quiere decir que los libros para el gusto de la mayoría tienen que ser, hablando en general, más bien simples, de escritura fácil y directa, que no exija casi ningún otro conocimiento. ${ }^{10}$

En el supuesto de que esto fuera así y Torri tuviera razón al señalar al lector de cuentos como ingenuo, los libros de relatos se venderían más que los de novela. Sin embargo, con base en las afirmaciones de Henríquez Ureña y Jacobo Siruela, la novela tiene mayor posibilidad de éxito editorial. Lo cual se confirma en los lugares comunes que existen en torno al acto de la lectura y su relación con la novela, como si todo momento de concentración del lector estuviera relacionado con tener un libro de largo aliento, no así con el cuento. Incluso en algunos relatos breves que tematizan al personaje lector, se le observa con una

\footnotetext{
${ }^{8}$ Julio Torri, estudio preliminar a Grandes cuentistas (México: Jackson INC Editores, 1968), ix.

${ }^{9}$ Rosa Beltrán, "Diálogo a treinta voces", Sólo Cuento 1 (2009): v.

${ }^{10}$ Fernando Escalante Gonzalbo, A la sombra de los libros: lectura, mercado y vida pública (México: El Colegio de México, 2007), 249.
} 
novela en sus manos. ${ }^{11}$ Parece que es en este género donde se cumple con un mayor estado de permanencia, que te convierte en lector. Asimismo, en la novela reciente de Fabio Morábito El lector a domicilio (2018), el protagonista es obligado a cumplir un deber comunitario de lectura en voz alta y, aunque intenta transmitir el género de la poesía, la exigencia común de su público es la novela.

"La novela tiene algo de almohada durable", mencionó Adolfo Bioy Casares como contestación a la pregunta: “¿Por qué la novela tiene, en general, una aceptación más rápida que el libro de cuentos por parte del lector común?". ${ }^{12}$ La comodidad del género extenso -sin cambios tajantes de atmósfera, en comparación con los "cambios de vehículo" que presenta el cuento- es una de las respuestas basadas en la composición formal de ambos tipos literarios. Pero existen también otras consideraciones desde el punto de vista del campo cultural.

En 1983 Roger Chartier y Pierre Bourdieu mantuvieron un debate en Radio France respecto a los problemas del libro y la lectura. Se cuestionan el "'etnocentrismo de la lectura' y la universalización de una forma de lectura que regularmente se corresponde con aquella que domina en los círculos de los intelectuales". ${ }^{13}$ Bajo esta mirada, el género del cuento no domina ese tipo de estratos intelectuales, a pesar de existir desde la antigüedad. Pero si habláramos de la dominante en los círculos infantiles y juveniles, es la forma cuentística la que desbancaría a cualquier otro tipo de textos. Y la razón está relacionada

${ }^{11}$ En la literatura hispánica se encuentran ejemplos de la novela como lugar común del acto de lectura; está el caso de "Continuidad de los parques" de Julio Cortázar, o un micro relato colombiano, "Un personaje en apuros", que rinde homenaje al argentino: "Las aventuras del personaje concentraban la atención de Leoncio en las páginas de la novela. El personaje huía de varios hombres armados que lo perseguían por callejuelas oscuras, saltando tapias, introduciéndose entre matorrales salvadores. Leoncio se aferraba al libro, excitado, haciendo suya la angustia del personaje. Los hombres acortaban a cada instante la distancia, con un tremendo esfuerzo, pues el personaje demostraba ser hábil, pero lograron por fin cercarlo contra una pared para concluir su propósito.

Leoncio no pudo reprimir su ansiedad.

-¡Deténganse! -gritó.

La escena quedó inmóvil. El personaje miró a Leoncio y le dijo:

-Es la primera vez que alguien interviene, pero mejor cállese: así la cuestión no funciona". Luis Fayad, "Un personaje en apuros", en La minificción en Colombia, comp. de Henry González (Bogotá: UPN, 2002), 57.

12 Adolfo Bioy Casares, "Acerca del cuento y la novela", en Teorías del cuento I, comp. de Lauro Zavala (México: UNAM, 2008), 47.

13 "La lectura: una práctica cultural. Debate entre Pierre Bourdieu y Roger Chartier", trad. de Renán Silva, Revista Sociedad y Economía 4 (2003): 161. 
con los criterios mencionados sobre la literatura oral, sumados al tono lúdico y la extensión corta. Pierre Bourdieu reflexiona sobre las intenciones de difusión a partir de las dimensiones:

Un texto de largos párrafos se dirige a un público más selectivo, que un texto cortado en pequeños parágrafos. Esto reposa sobre la hipótesis de que un público más popular pedirá un discurso más discontinuo, etc. Así, la oposición entre largo y corto, que puede manifestarse de múltiples maneras, constituye una indicación sobre el público imaginado y al mismo tiempo una indicación sobre la idea que el autor tiene de sí mismo. ${ }^{14}$

Sin embargo, sobre lo que aquí importa reflexionar es cómo el cuento (no infantil) se posiciona dentro del etnocentrismo de la lectura mencionado por los expertos. Pues no significa que esté ausente, pero ¿de qué manera es visible? Donde el cuento sí ha tenido un auge es en las publicaciones periódicas.

\section{Revistas y antologías}

Como dice Liliana Pedroza, "si bien el cuento no es el género mejor acogido por las editoriales, en México ha encontrado aliados en revistas y antologías". ${ }^{15}$ Una de las posibles razones la explica Russell Cluff en su artículo "Historia de una tradición: el cuento enlazado en México", donde se remonta al pasado y explica que "la circunstancia del cuento como género literario durante la primera mitad del siglo XIX no permitía que se editara en forma de libro, pues recién se estaba gestando el género en Hispanoamérica y su existencia dependía de los periódicos". 16

Pero otra de las posibles razones la explica Juan Armando Epple al señalar que el cuento moderno estuvo vinculado a las demandas y opciones de las revistas, las cuales fueron creando un mercado para este tipo de ficción. El espacio limitado que requería el formato se confundió con el rasgo de la brevedad: era importante rellenar algunos espacios al momento de la compaginación. Por ejemplo, "los micro-cuentos que publicó Rubén Darío a comienzos de

\footnotetext{
14 Ibid., 165.

15 Liliana Pedroza, Historia secreta del cuento mexicano (1910-2017) (Monterrey: UANL, 2018), 45.

${ }^{16}$ Russell Cluff, "Historia de una tradición: el cuento enlazado en México", en El ojo en el caleidoscopio, ed. de Pablo Brescia y Evelia Romano (México: UNAM, 2006), 192.
} 
siglo parecen obedecer a esta factura por encargo". ${ }^{17}$ Otro caso concreto donde los espacios de la página invitan a ser rellenados por la brevedad se encuentra en El Cuento. Revista de Imaginación, dirigida por Edmundo Valadés, publicación que no sólo se dedicaba al género, sino también a relatos muy breves que cubrían ciertos huecos de las planas, de ahí el nombre de la sección "Caja de Sorpresas".

La primera época de esta revista apareció en 1939 en las oficinas de la revista Hoy. En esta etapa tan sólo tuvieron cinco entregas, es hasta su segunda época, en 1964, cuando arrancan de manera definitiva. El objetivo de El Cuento era "proporcionar mensualmente una selección de cuentos cortos para familiarizar al lector con la mejor literatura". ${ }^{18}$ El 4 de agosto de ese año Valadés abrió la primera Convocatoria del Concurso de Cuento Brevísimo. Su recepción y éxito son visibles en la sección de correspondencias de la misma revista, "Cartas y Envíos", donde se comentaba cada uno de los textos enviados, sus razones de inclusión en la revista o, como ocurría con la mayoría, los motivos de exclusión: "Escribe usted bien, describe bien además, pero para que su texto fuera cuentístico, le sugerimos suprimir las dos cuartillas iniciales, del todo innecesarias y las tres líneas finales. Demasiado tremendista su cuento: tales descripciones de seres y ambientes repugnantes, acaba por no ir a ningún lado".19

Los 143 números de esta revista, que contaba con consejeros editoriales como Henrique González Casanova y Juan Rulfo, contradicen la idea de que el cuento quede fuera del etnocentrismo de la lectura. Y con la gran constancia de los concursos representada por las cartas, también se hacen visibles los alcances y demandas respecto al género, mientras que de las respuestas del comité se desprenden los elementos legítimos y se consolida una poética respecto a lo que merece ganar.

Michael Bhaskar menciona que "la edición es donde se seleccionan las obras, a partir de agentes concretos, de acuerdo con cierto modelo, o, mejor dicho, modelos". ${ }^{20}$ Bajo esta mirada, los concursos de cuento convocados por la revista de Valadés no sólo hablan de una poética, sino también de una forma de filtrado. Aunque se tomen como ejemplo los de esta revista, cualquier certamen

\footnotetext{
17 Juan Armando Epple, "Introducción”, Revista Interamericana de Bibliografía 4 (1996): 13.

${ }^{18}$ Armando Pereira, Diccionario de la literatura mexicana. Siglo XX (México: UNAM, 2004), 119.

${ }^{19}$ El Cuento. Revista de Imaginación, núm. 117 (enero-marzo de 1991): X.

${ }^{20}$ Michael Bhaskar, La máquina de contenido: hacia una teoría de la edición desde la imprenta hasta la red digital (México: FCE, 2014), 128.
} 
de cuento es una forma de difusión del mismo, que funciona acertadamente gracias a su formato corto. Si bien existen concursos de novela, teatro y poesía, los de cuento no solamente se aprecian en las convocatorias estatales o nacionales, diferentes instituciones recurren a ellos no sólo como apremio de la forma literaria, sino también para divulgar su cultura institucional. La razón va de la mano con lo subrayado por Bhaskar para la edición: la selección de un modelo ejemplar.

Por un lado, se espera que el texto sea representativo del género, mientras que el jurado, que teóricamente también debe ser ejemplar, cumple con el rol de editor. La atmósfera de competitividad inherente a un concurso está relacionada con un ideal del modelo ejemplar, por ello un certamen es una forma de difusión tanto del género, de la institución, como de la misma cultura: es sólo lo representativo lo que se busca difundir. En consecuencia, la recepción del cuento puede estudiarse a partir de los concursos, no únicamente por su demanda de participación sino también porque su conformación, estructura y premiación implican una poética, un juicio respecto a cómo debe ser o no ser el género.

Respecto a la publicación de cuentos en revistas, Rosa Beltrán explica que aunque el género sea una especie en extinción, no quiere decir que se dejen de escribir cuentos extraordinarios, lo que sucede es que "por momentos, estos parecen no hallar cobijo para su publicación en libros". ${ }^{21}$ Por tal razón Beltrán dirige la publicación de una antología con periodicidad anual editada por la Dirección de Literatura de la Coordinación de Difusión Cultural de la UNAM: Sólo Cuento. Este trabajo iniciado en 2009 reúne autores en plena producción cuentística y, dado que todo universo tiene su propio etnocentrismo o autoridad, cada número está coordinado y prologado por cuentistas mexicanos representativos como Cecilia Eudave, Antonio Ortuño y Mónica Lavín, por mencionar a los coordinadores de los últimos tres números.

Sólo Cuento es un híbrido interesante, pues tiene periodicidad como las revistas, pero no se trata de este tipo de publicaciones, sino de antologías, por lo cual después de un prólogo que defiende al género y explica el contenido, los cuentos hablan por sí solos. Por su parte, la revista El Cuento también dejaba que los relatos hablaran por sí mismos, es decir que no conviven con ensayos u otros géneros. Quizá la diferencia importante entre estas dos publicaciones se observa en la cantidad de páginas: alrededor de unas 130 comparadas con las casi 500 de Sólo Cuento, y la periodicidad, pues la revista de Valadés tuvo que

${ }^{21}$ Beltrán, "Diálogo a treinta voces", vi. 
espaciar sus números mensuales a semestrales. Pero, en conjunto, esa revista pionera no deja de ser también una antología. Estos dos casos se distinguen de otras publicaciones literarias que conjugan varios géneros y entre ellos puede aparecer o no el cuento, pero la de Valadés y la de la UNAM se concentran en este género.

La publicación del cuento en antologías tiene su justificación en la idea de completitud y a la vez de representatividad, pues es la promesa de una selección prolija, el epítome que congrega textos para generar una visión de unidad. Las antologías se ordenan por líneas, ya sea temporales, regionales, de un único autor o temáticas. La necesidad estructural donde la diversidad de textos debe ajustarse a un eje, representa la necesidad de durabilidad, coherencia y unidad a la que invita la novela. ${ }^{22}$

En Quince hipótesis sobre géneros Alberto Vital menciona que existen géneros ligados a la independencia de una nación, como es el caso de la novela de la Revolución para México, en la cual sobresale la épica nacional, que requiere de una larga extensión. "Le es sustancial a la épica la extensión. La amplitud, la vastedad". ${ }^{23}$ Pero también hay géneros breves que transportan la épica, es decir que la estructura breve tiene rasgos de la vastedad, de la durabilidad, de tal modo que al combinarse con otros podrá generar la unidad que de manera aislada no encuentra. Las antologías contribuyen a generar esta idea que ubica al lector en un punto de mira, ofreciendo parte del horizonte.

Al respecto, Freja Cervantes y Pedro Valero señalan que:

Desde el siglo XIX la tradición antológica había resultado ser un producto efectivo para la comercialización. Probada en principio por el folletín coleccionable de las prensas periódicas, solía alcanzar el formato del libro, circular con relativa facilidad y ser apropiada por públicos más amplios. [...] El efecto de conjunto de toda antología se resuelve en su intención panorámica, cuyo andamiaje historiográfico se infiere, o bien de forma programática, para irrumpir en la tradición y reinsertarse en ella delimitando, ampliando o segmentando su alcance. ${ }^{24}$

${ }^{22}$ Como ejemplo de las antologías de cuento sobresale, por su amplio marco temporal: Dos siglos de cuento mexicano, XIX y XX, de Jaime Erasto Cortés. México: Promexa, 1979.

${ }^{23}$ Alberto Vital, Quince hipótesis sobre géneros (México: UNAM, IIFI / UNAL, 2012), 75.

${ }^{24}$ Cervantes y Valero, La colección Cvltvra, 46. 
La palabra antología proviene de las palabras flor y selección, es decir, "la acción de reunir flores selectas". ${ }^{25}$ Con el supuesto de que los cuentos se encuentran más fácil en este tipo de publicaciones, convendría preguntarse sobre su cualidad de "manojo", que en primera instancia responde a la brevedad, pero también a una dualidad: los cuentos en conjunto pueden ser leídos como una obra o distintas obras. En La era neobarroca Omar Calabrese señala la distinción entre el fragmento y el detalle, que resulta útil para reflexionar sobre los significados de los trozos que componen una obra o cuestionar si una antología de cuentos es una obra en sí o un conjunto de textos. La palabra detalle "viene del francés renacentista 'detail', es decir, 'cortar de'. Esto presupone, por tanto, un sujeto que corta un objeto". ${ }^{26}$ Por ello siempre habrá una relación perceptible del detalle con el todo, algo que lo ligue. En cuanto al fragmento, "deriva del latín 'frangere', es decir, 'romper'. [...] A diferencia del detalle, el fragmento, aun perteneciendo a un entero precedente no contempla su presencia para ser definido, más bien: el entero está in absentia". ${ }^{27}$ En sí, el detalle es dependiente de un todo y el fragmento es autónomo. Las antologías de cuento, en consecuencia, están compuestas de fragmentos, no en el sentido de ruptura sino de independencia, pues cada cuento guarda su coherencia. No obstante, los ejes temáticos, por ejemplo, dan la idea de organicidad y posible interconexión entre cada texto.

En El ojo en el caleidoscopio Pablo Brescia y Evelia Romano invitan a fijar la mirada sobre las colecciones de textos integrados: "aquellos libros cuyos textos presentan cierta continuidad [...]. Esta variante narrativa se ha ensayado con asiduidad en la práctica literaria latinoamericana". ${ }^{28}$ Sobre todo se refieren a las secuencias o textos enlazados por la repetición de asuntos, temas o personajes, o sea a los detalles que sí guardan una relación con un todo pero, de manera dual, pueden comprenderse por separado. Al respecto, Russell Cluff propone como ejemplos Tiempo cercado de Sergio Pitol, La banda de los enanos calvos de Agustín Monsreal o La semana de colores de Elena Garro.

\footnotetext{
${ }^{25}$ José Antonio Sabio Pinilla, "¿Es la antología un género? A propósito de las antologías sobre la traducción", acceso el 7 de octubre de 2019, https://www.academia.edu/1912731/_ Es_la_antolog\%C3\%ADa_un_g\%C3\%A9nero_A_prop\%C3\%B3sito_de_las_antolog\% C3\%ADas_sobre_la_traducci\%C3\%B3n.

${ }^{26}$ Omar Calabrese, La era neobarroca (Madrid: Cátedra, 1994), 86.

27 Ibid., 88-89.

${ }^{28}$ Pablo Brescia y Evelia Romano, "Estrategias para leer textos integrados", en El ojo en el caleidoscopio (México: UNAM, 2006), 8.
} 
Las colecciones de cuentos, las antologías de varios autores o aquellas de un único autor, van a cuestionar la idea de unidad; sin embargo, de manera paradójica, ese manojo de flores constituido por un formato breve, de efecto único en el lector, no sólo es una unidad en sí misma, sino también en combinación. Estas tres formas son opciones de ordenamiento de los cuentos, un modo de darles salida, pero no por ello son capítulos que igualen a la novela.

\section{Bibliografias del cuento}

Una vez mencionada la importancia de las revistas y antologías, conviene remontarse a los primeros trabajos bibliográficos que reúnen exclusivamente la relación de títulos de libros de cuento. Aunque el concepto de exclusividad es imposible de aplicar a los géneros literarios -y mucho menos al que aquí se revisa, pues su cualidad híbrida lo emparenta con la novela corta, el ensayo y la prosa poética-, las bibliografías del cuento son un punto de partida para estudiar el género respecto a su cantidad, es decir, el número de títulos y reediciones, así como las casas editoras de determinada época, para responder la pregunta sobre dónde o quién apuesta por su publicación.

La bibliografía, entendida a grandes rasgos como la descripción de libros, ${ }^{29}$ produce un efecto parecido al de las antologías: los nombres de autores y títulos de libros que llegan a ambos compendios han pasado por un proceso de solidificación que les permite asentarse junto a otras obras similares. Esto no quiere decir que todos los textos incorporados sean canónicos, pero para llegar al compendio o a la lista se necesita un tiempo de recepción. Así como las antologías generan un panorama literario, las bibliografías, desde esta perspectiva, generan un panorama editorial.

Incluso tanto el antólogo como el bibliógrafo asumen el papel de juez para conformar su trabajo, el cual va de la mano con la inevitable discriminación en el sentido de selección. Al respecto, Chávez Castañeda y Celso Santajuliana mencionan:

\footnotetext{
29 "Hacia el siglo XVIII en Francia, el término adquirió el significado de escribir acerca de los libros y es así como hasta ahora se entiende a la bibliografía, claro está, ampliando el concepto para abarcar todo tipo de materiales bibliográficos", Hugo Figueroa, "Panorama de la bibliografía", en Recursos bibliográficos y de información, coord. de Hugo Figueroa y César Ramírez (México: UNAM, FFyL, 2006), 48.
} 
Siempre llega un momento en que el medio literario comienza a prestar atención a sus nuevas camadas de escritores, y la atención trae aparejada la categorización y la discriminación. Cuando alguien de la generación o de otra generación se autodefine como juez, por ejemplo, antologando o inventariando [...], es difícil evadirse de los efectos de esta lógica de inclusión-exclusión que se echa a andar y de las operaciones de rotulación externa. ${ }^{30}$

La diferencia importante es que las antologías se rigen por un criterio de exclusión más marcado que las bibliografías, estas últimas mientras más incluyen mejor funcionan, y las primeras apuestan por autores que, idealmente, permanecerán a lo largo del tiempo, por tanto se trata de una selección más prolija. Como menciona Martha Elena Munguía, las antologías "se han constituido en uno de los factores fundamentales para el establecimiento del canon genérico al incorporar reiteradamente ciertos textos y excluir otros". ${ }^{31}$ En cambio, las bibliografías se sustentan en un criterio de inclusión. Hugo Figueroa las equipara con un universo donde cada elemento (autores, obras, textos) deja de estar aislado para interconectarse con más universos bibliográficos. Si bien existen dos tipos de bibliografía, una analítica y otra enumerativa, en cada una puede apreciarse el esfuerzo por concentrar el flujo de información y, sobre todo, permiten comprender "cómo, por qué y a través de qué medios ha llegado determinado texto a nuestras manos". ${ }^{32}$

Cuando Michael Bhaskar narra la historia de los primeros editores, comenta que en el siglo XV "editar e imprimir eran actividades prácticamente indistintas, con las funciones de producir un libro confundidas con las de publicarlo". ${ }^{33}$ De igual forma, la disciplina de la bibliografía ha pasado por un proceso de evolución; ya sea aquella que comenta críticamente los títulos o la que únicamente enlista, se trata de una práctica cuyas intenciones se van modificando. En la época novohispana se hacían listas de libros para llevar un control de los productos traídos de España, prohibir ciertos títulos, enlistar lo que se compraba y vendía, señalar lo publicado o adquirido por frailes y conventos, llevar control de lo publicado por las primeras imprentas. Pero fue en el siglo XIX cuando la disciplina

\footnotetext{
${ }^{30}$ Ricardo Chávez Castañeda y Celso Santajuliana, La generación de los enterradores. Una expedición a la narrativa mexicana del tercer milenio (México: Nueva Imagen, 2000), 120.

${ }^{31}$ Martha Elena Munguía Zatarain, Elementos de poética histórica: el cuento hispanoamericano (México: El Colegio de México, 2002), 16.

${ }^{32}$ Figueroa, "Panorama de la bibliografía", 47.

${ }^{33}$ Bhaskar, La máquina de contenido, 14.
} 
comenzó a afinarse y, en consecuencia, surgieron las bibliografías especializadas, con exclusividad en una sola materia.

Así como ha habido una evolución de la bibliografía y de la edición, es posible observar un avance en las bibliografías mexicanas dedicadas exclusivamente a géneros literarios. En la Bibliografía de la novela mejicana compilada por Arturo Torres-Rioseco, en 1933, se aclara un plan de trabajo "que incluiría la lírica, la novela y el drama mejicanos". ${ }^{34}$ La ausencia del cuento que determina el compilador se debe a una falta de representatividad: nuestro género queda fuera del etnocentrismo de la lectura, como se mencionó. Y, por otro lado, la división que establece Torres-Rioseco consiste en lírica, drama y narrativa; en consecuencia, con darle espacio a la novela ya se cubre ese último sector. ${ }^{35}$

La Bibliografía del cuento mexicano de Luis Leal, publicada en 1958 por Ediciones de Andrea, es la primera en la historia de la bibliografía mexicana dedicada al cuento. Sus antecedentes, como indica la introducción, son la mencionada bibliografía de Torres-Rioseco, la Bibliografía de novelistas (1926) de Juan Iguíniz y los Poetas nuevos de México (1916) de Genaro Estrada. Luis Leal advierte, en su propio trabajo, la omisión de novelas cortas y leyendas, porque ya se encuentran enlistadas bajo novelistas, aclaración que permite observar también los conceptos literarios que se tenían en los años 50 respecto a los límites genéricos: los libros de cuento podían compartir las listas con otros géneros narrativos, pues las demarcaciones se diluyen. Aunque la hibridez sigue estando vigente, la cantidad de obras crece, por lo que delimitar los criterios entre una y otra forma literaria es necesario para los trabajos bibliográficos.

En la Bibliografía de Luis Leal llama la atención la gran cantidad de cuentos publicados en revistas y periódicos; lo cual es comprensible, como se mencionó, dada la naturaleza estructural de los textos, es decir, el formato corto. Pero en cuanto a editoriales, las que sobresalen por su repetición son: Costa-Amic, Botas y Canek. En menor medida: Stylo, Cvitvra, Séneca, Jus, Imprenta Juan Pablos, Librería de la viuda de Ch. Bouret y el Fondo de Cultura Económica.

En 1988 Emmanuel Carballo publicó Bibliografía del cuento mexicano del siglo XX, gracias a la Coordinación de Difusión Cultural de la UNAM y en la colección Materiales de Extensión Universitaria. El especialista aclara que sus fuentes

\footnotetext{
${ }^{34}$ Arturo Torres-Rioseco, Bibliografía de la novela mejicana (Cambridge: Harvard, 1933), vii.

35 Torres-Rioseco justifica la limitación de su trabajo, pues la Bibliografía del teatro en México de Francisco Monterde fue publicada en el mismo año de 1933; además, los libros de poesía son numerosos, por tanto él decide concentrarse únicamente en la bibliografía de la novela.
} 
fueron: Bibliografía del cuento mexicano de Luis Leal, Bibliografía de novelistas de la Revolución mexicana de Ernest Moore (1941), nuevamente la Bibliografía de la novela mejicana de Arturo Torres-Rioseco y la biblioteca particular de Francisco Guzmán Burgos, editor de la obra.

Por su momento de publicación, la Bibliografía de Carballo abarca de 1900 a 1987. A diferencia del trabajo de Luis Leal, ya no enlista obras hemerográficas, no porque no existan, sino con la intención de acotar la mirada hacia los libros impresos. A principios de siglo publicaban las mismas imprentas, por lo que sobresale la de Victoriano Agüeros o la de Ch. Bouret. Encontramos, además, la Tipografía de Valadés, la Tipografía Literaria de Filomeno Mata y la de la viuda de Francisco Díaz de León. Mientras que yendo hacia la década de los años 80, que es hasta donde llega el catálogo de Carballo, resulta interesante la aparición de editoriales universitarias - la Universidad Veracruzana y la UNAM-, así como instancias estatales y gubernamentales: los gobiernos del Estado de México, de Jalisco, Toluca y Tabasco; las delegaciones Venustiano Carranza y Cuauhtémoc de la Ciudad de México; la Secretaría de Educación Pública, el Fondo de Cultura Económica y Joaquín Mortiz.

Como dijimos, "el cuento encuentra cobijo en las antologías" y el trabajo de compilación y selección se estrecha con el de los registros bibliográficos, sobre todo debido a la información ya capturada, por lo cual no es gratuito que los principales bibliógrafos del cuento en México, Luis Leal y Emmanuel Carballo, hayan publicado también antologías. En este rubro, el primero publicó Breve historia del cuento mexicano (1956), Antología del cuento mexicano (1957) y El cuento veracruzano (1966); el segundo, El cuento mexicano del siglo XX: antología (1964).

Además de los dos trabajos bibliográficos dedicados al cuento, Russell Cluff presentó un Panorama crítico-bibliográfico del cuento mexicano (1950-1995), a partir del cual llegó a una conclusión numérica y precisa: "La década de los 50 rindió un total de 201 libros de cuento; la de los 60, 248; la de los 70, 251; la de los 80,580 . Esto representa un ascenso en la publicación de libros del 19\% entre los años 50 y 60; del 1\% entre los años 60 y 70; y del 57\% entre los 70 y 80 [...]. En lo que va de la década de los 90 tengo registrados 304 libros". ${ }^{36}$ Esta comparación por décadas constituye un ejemplo de la posibilidad de estudiar el incremento de publicaciones, al tiempo que expresa un desarrollo y prolifera-

\footnotetext{
${ }^{36}$ Russell Cluff, Panorama crítico-bibliográfico del cuento mexicano (1950-1995) (Tlaxcala: Universidad Autónoma de Tlaxcala, 1997), 51.
} 
ción del género. Sin embargo, la investigación de Cluff se trata más bien de una revisión crítica, con comentarios a la obra de autores representativos, por lo que no se incluye aquí como trabajo de bibliografía.

El mismo año que Carballo publica su Bibliografía también salen a la luz dos diccionarios importantes, pero no son exclusivos del cuento, sino de la literatura mexicana en general, se trata del primer tomo del Diccionario de escritores mexicanos siglo XX. Desde las generaciones del Ateneo y novelistas de la Revolución hasta nuestros días (UNAM, IIFL, 1988) de Aurora Ocampo, y el Diccionario bio-bibliográfico de escritores de México (INBA, 1988) de Josefina Lara Valdez. En la introducción del último se habla explícitamente del primero como un trabajo de próxima publicación que contendría, a diferencia del de Lara, explicaciones críticas. La coincidencia de tres trabajos bibliográficos presentados el mismo año se relaciona con la estabilidad de las instancias gubernamentales y universitarias que los publicaron, y la vastedad literaria que implica ser registrada y ordenada.

Después del año bibliográfico de 1988, transcurrieron tres décadas para que volviera a aparecer una bibliografía dedicada al cuento: se trata de Historia secreta del cuento mexicano 1910-2017 de Liliana Pedroza, publicada por la Universidad Autónoma de Nuevo León. Desde una perspectiva de género, reúne exclusivamente a mujeres cuentistas que han publicado en ese periodo. El resultado tangible es la reunión de 512 autoras, 856 libros y 312 antologías. Aunque la intención principal de este volumen es hacer visibles a las escritoras, dentro de los resultados también se encuentra el rescate de un género literario que tampoco ha sido muy estudiado de manera bibliográfica.

En el caso de la Bibliografía de Liliana Pedroza, en la primera mitad del siglo XX son constantes las publicaciones hechas por Cvltvra, Costa-Amic, Stylo, Botas y Ediciones de Andrea. Hacia la segunda mitad no podían faltar Joaquín Mortiz, Fondo de Cultura Económica, Grijalbo, ERA, y Cal y Arena. A las ediciones universitarias que ya habían sido rescatadas por Carballo se unen la Universidad de Guadalajara, Universidad Autónoma de San Luis Potosí, Universidad Autónoma de Sinaloa y Universidad Autónoma Metropolitana, además de secretarías de cultura, como la de Jalisco y el Instituto Mexiquense de Cultura. En la década de los 90 sobresale Conaculta, con Fondo Editorial Tierra Adentro, en tanto que a finales del siglo XX y en el presente XXI son visibles las editoriales independientes que publican cuento: Ficticia, Tinta Nueva, Arlequín, Almadía, Fósforo, Posdata, Tumbona, Kodama Cartonera, Cuadrivio, Paraíso Perdido, Sexto Piso, Textofilia y La Tinta del Silencio. 
Por último, los trabajos bibliográficos que recuerdan la relación de la disciplina con las antologías, son precisamente los que dan exclusividad a las colecciones de cuento: Jaime Erasto Cortés, en su libro Del gusto y la memoria. Ensayos sobre cuento mexicano (2012), dedica un capítulo a las "Antologías de cuento mexicano", donde es posible encontrar no sólo una bibliografía, sino también comentarios críticos y explicaciones sobre su trascendencia. ${ }^{37}$ Lauro Zavala, en Paseos por el cuento mexicano contemporáneo (2004), presenta una bibliografía de 100 títulos de antologías que abarca desde 1988 hasta 2003, con una útil división en: generales, publicadas en el extranjero, regionales, genéricas, temáticas y especializadas. ${ }^{38}$ La lista de antologías es consecuente con el género del cuento, pues si su difusión es por medio de este tipo de publicaciones, la bibliografía de compendios se vuelve necesaria.

\section{Editoriales y sus colecciones}

Al hacer una comparación entre las bibliografías de Leal, Carballo y Pedroza es posible observar un cambio en cuanto al tipo de editoriales mexicanas que han apostado por el cuento. En los años 30 y 40 despuntaban Cvltvra, Botas y Costa-Amic, mientras que en los 60 lo hacen Joaquín Mortiz y el Fondo de Cultura Económica. Además, es visible que hacia la segunda mitad del siglo XX, el contexto sociocultural permite que las universidades e instancias gubernamentales formen parte de la trayectoria editorial, lo cual indica un trabajo distinto al de las imprentas que dominaban la actividad económica a inicios del siglo. Al respecto, Camilo Ayala menciona:

En 1987, la UNAM creó un programa para apoyar la promoción y difusión de las publicaciones de diversas instituciones de educación superior. Estas instituciones acordaron la formación de una Red Nacional de Editoriales Universitarias que dejó de funcionar en 1993. En 1999 se formó, a través de una iniciativa de la Asociación Nacional de Universidades e Instituciones de Educación Superior, Altexto, Alianza del Texto Universitario, que se convirtió en 2007 en la Red Nacional Altexto y actualmente está integrada por 42 instituciones. ${ }^{39}$

\footnotetext{
37 Jaime Erasto Cortés, Del gusto y la memoria. Ensayos sobre cuento mexicano (Jalapa: UV, 2012).

${ }^{38}$ Lauro Zavala, Paseos por el cuento mexicano contemporáneo (México: Nueva Imagen, 2004).

${ }^{39}$ Camilo Ayala Ochoa, La cultura editorial universitaria (México: UNAM, 2015), 21.
} 
Sumado a lo anterior, en la bibliografía más reciente, la de Pedroza, observamos el surgimiento de las "editoriales independientes". A pesar del nombre, la idea de independencia es un tanto debatible, pues los recursos económicos deben provenir de una fuente, requieren apoyos de becas estatales o coediciones con otras casas editoras. Y comparar el enorme catálogo de Sexto Piso, inaugurada en 2002, con la joven trayectoria de La Tinta del Silencio que inicia en 2011, demuestra una gran diferencia entre ambas empresas que portan el título de independientes..$^{40}$

Lo que importa subrayar aquí es que con la bibliografía que abarca hasta el 2017 se observan las apuestas de pequeñas editoriales independientes, así como las de trayectoria, de la mano de ediciones estatales, universitarias y con mayor historia como el Fondo de Cultura o ERA. Ahora bien, una vez identificadas estas casas en cuanto a su credibilidad por el género cuentístico, llaman la atención aquellas que han delimitado sus colecciones a la exclusividad del cuento. Esta iniciativa resalta la apuesta por el género, pues para formar una colección se requiere de una pluralidad de volúmenes que la sostengan, por ello no cualquier editorial toma ese riesgo; en ocasiones es más factible la colección de narrativa que combine novela, ensayo y cuento, como lo hace Almadía en su colección Mar Abierto.

Como ejemplo de colecciones universitarias, en los años 60 la UNAM inició Cuento y Relato, donde aparecieron obras de Augusto Monterroso, Carlos Valdés, Arturo Souto, Alberto Bonifaz Nuño y Eduardo Lizalde, entre otros. Dentro de esta colección se abrió la serie Confabuladores, título inspirado en el libro Confabulario del gran cuentista Juan José Arreola, y dedicó "sus páginas a colecciones de textos breves donde la prosa alcanza intensidad y altura y vuelve presente la irónica pregunta de Stephane Mallarmé: '¿En verdad existe la prosa?"'.41 La serie fue coeditada con la Dirección de Literatura de la Coordinación de Difusión Cultural hasta el año 2005.

Respecto a las ediciones gubernamentales, y así como Confabuladores tiene su base en la obra de Juan José Arreola, Conaculta también nombró una de sus colecciones bajo el mismo criterio: la colección Guardagujas que comenzó en 1988. Sin embargo, a pesar del nombre, no tiene exclusividad en el cuento, sino que se abre a la narrativa en general. El catálogo del 2001 la describe: "Fiel

\footnotetext{
${ }^{40}$ Sobre el tema de las editoriales independientes en México puede consultarse la tesis "Campo literario mexicano: literatura y edición independiente", de Alma Patricia Salinas Pérez (UNAM, 2017).

${ }^{41}$ Catálogo. Colecciones de la Coordinación de Humanidades (México: UNAM, 1998), 123.
} 
a la vocación originaria de la literatura, esta colección pone de relieve el eterno oficio de narrar y congrega a las más diversas voces de la narrativa en nuestra lengua". ${ }^{2}$ Asimismo, aunque Fondo Editorial Tierra Adentro suele publicar libros de cuento, sus criterios y descripción tampoco se cierran a este género, pues su objetivo es "impulsar la creación literaria de autores jóvenes". ${ }^{43}$

Por otro lado, el Fondo de Cultura Económica tiene una amplia lista de libros de cuento, pero no sólo conviven con la novela sino con una gran variedad de géneros literarios. Los libros de cuento están en las colecciones: Letras Mexicanas, Lecturas Mexicanas, Cenzontle, Tezontle, Colección Popular y Tierra Firme, al igual que en obras reunidas y ediciones conmemorativas. De este último rubro, por ejemplo, en su 70 aniversario el FCE publicó en 2005 a tres cuentistas representativos: Juan José Arreola, Francisco Rojas y Edmundo Valadés, además de una antología, El cuento hispanoamericano. Antología críticohistórica, de Seymour Menton.

Por último, entre las editoriales independientes sobresale Ficticia, pues sí tiene una colección exclusiva de cuento, cuyo título no deja lugar a dudas: Biblioteca del Cuento Contemporáneo, que hasta el segundo semestre de 2019 había publicado 63 libros cuentísticos. Esta casa editora inició en 1999, por lo cual un trayecto de 20 años le ha dado la posibilidad de llegar a este número, a favor del género. Desde sus inicios la apuesta fue evidente y aunque tiene otras colecciones de ensayo, novela, ciencias sociales y humanidades, además de que publica algunos premios convocados por el Instituto Nacional de Bellas Artes, la mayoría de sus ediciones giran en torno al cuento.

\section{Conclusiones}

En páginas anteriores se planteó la discusión sobre la efectiva o equivocada recepción del cuento: que requiere de una competencia ajena al lenguaje del mercado (Rosa Beltrán), o está dirigido a un lector ingenuo y, al ser breve, a un público popular (Torri, Bourdieu). Entre estas conjeturas de recepción, opuestas entre sí, pero valiosas en tanto que suman miradas sobre el mismo objeto, sobresalen también las listas bibliográficas, las publicaciones periódicas, las antologías y editoriales que demuestran de qué manera esta forma literaria se encuentra vigente en el presente. Independientemente de que el éxito editorial

\footnotetext{
${ }^{42}$ Catálogo dosmiluno (México: Conaculta, DGP, 2001), 111.

43 Ibid., 147.
} 
sea la novela, como lo señala Jacobo Siruela, los cuentos perduran en el transcurso del tiempo.

Si bien es necesario profundizar en la lista de editoriales y sus criterios, hasta aquí ha sido posible demostrar que aunque el cuento está condenado a una "muerte súbita", como señala Rosa Beltrán, hasta la fecha esa muerte no ha ocurrido. Después de todo, el "cobijo" en revistas y antologías continúa, sin contar la difusión del género en Internet -que en este trabajo no fue retomada-, pero su cualidad de brevedad permite que el cuento encuentre espacios virtuales. También es cierto que ya no existen eventos representativos como el Encuentro Internacional de Investigadores de Cuento de la Universidad Autónoma de Tlaxcala, que convocó Alfredo Pavón hasta el año 2000; no obstante, las apuestas editoriales siguen con vida y las bibliográficas han llegado hasta la revisión del 2017. Incluso, con los breves datos expuestos aquí: la antología Sólo Cuento, la bibliografía de Liliana Pedroza, las colecciones mencionadas y las editoriales independientes apostando por el cuento en la actualidad, ya es posible contradecir la condena del género.

Respecto a su cualidad híbrida, parecería que la posibilidad de esta forma literaria por compartir el espacio de publicación con otros géneros narrativos es un aspecto negativo, sin embargo, es su potencialidad para ser publicado y difundido. De cualquier forma, es visible un avance que no cambia al género, pero sí la manera de entenderlo, pues desde 1958 los libros de cuento se separan de otro tipo de bibliografías de narrativa que incluían novela corta o leyendas; es decir, que el género va adquiriendo ejemplos suficientes para emprender el trabajo bibliográfico. Ahora bien, las demarcaciones genéricas van de la mano con la mixtura del cuento, pero también con un proceso de representatividad: cuando son frecuentes las antologías del cuento, cuando se requiere hacer catálogos para demostrar su vastedad y cuando las editoriales universitarias, estatales e independientes lo publican, significa que el género se va solidificando, a diferencia de otras épocas como el siglo XIX, tiempo en el que era común encontrarlo sólo en revistas.

Por último, llama la atención que así como el género del cuento se va asentando y cobra representatividad, las bibliografías y las apuestas editoriales también han evolucionado a favor de la literatura, y en parte por el cuento. Las primeras debido a su forma de especializarse en materias concretas, lo que generó una concentración específica en el tema narrativo, y las segundas por abrir la variedad de opciones de publicación: desde comerciales y gubernamentales hasta educativas. El etnocentrismo de la lectura a favor de la novela permanece, 
pero no a modo de obstáculo para los demás géneros, de manera útil es un contrapeso que a la vez abre caminos.

\section{Referencias}

Anderson Imbert, Enrique. Teoría y técnica del cuento. Buenos Aires: Ariel, 1992.

Ayala Ochoa, Camilo. La cultura editorial universitaria. México: Universidad Nacional Autónoma de México, 2015.

Beltrán, Rosa. "Diálogo a treinta voces". Sólo Cuento 1 (2009): v-viii.

Bhaskar, Michael. La máquina de contenido: hacia una teoría de la edición desde la imprenta hasta la red digital. México: Fondo de Cultura Económica, 2014.

Bioy Casares, Adolfo. "Acerca del cuento y la novela". En Teorías del cuento I. Compilación de Lauro Zavala, 41-47. México: Universidad Nacional Autónoma de México, 2008.

Brescia, Pablo y Evelia Romano. "Estrategias para leer textos integrados". En El ojo en el caleidoscopio. Edición de Pablo Brescia y Evelia Romano, 7-43. México: Universidad Nacional Autónoma de México, 2006.

Calabrese, Omar. La era neobarroca. Madrid: Cátedra, 1994.

Carballo, Emmanuel. Bibliografía del cuento mexicano del siglo XX. México: Universidad Nacional Autónoma de México, 1988.

Catálogo. Colecciones de la Coordinación de Humanidades. México: Universidad Nacional Autónoma de México, 1998.

Catálogo dosmiluno. México: Consejo Nacional para la Cultura y las Artes, Dirección General de Publicaciones, 2001.

Cervantes, Freja y Pedro Valero. La colección Cvltvra y los fundamentos de la edición mexicana moderna (1916-1923). México: Juan Pablos / Secretaría de Cultura, 2016.

Chávez Castañeda, Ricardo y Celso Santajuliana. La generación de los enterradores. Una expedición a la narrativa mexicana del tercer milenio. México: Nueva Imagen, 2000.

Cluff, Russell. "Historia de una tradición: el cuento enlazado en México". En El ojo en el caleidoscopio. Edición de Pablo Brescia y Evelia Romano, 185-223. México: Universidad Nacional Autónoma de México, 2006.

Cluff, Russell. Panorama crítico-bibliográfico del cuento mexicano (1950-1995). Tlaxcala: Universidad Autónoma de Tlaxcala, 1997. 
Cortés, Jaime Erasto. Dos siglos de cuento mexicano, XIX y XX. México: Editorial Promexa, 1979.

Cortés, Jaime Erasto. Del gusto y la memoria. Ensayos sobre cuento mexicano. Jalapa: Universidad Veracruzana, 2012.

El Cuento. Revista de Imaginación, núm. 117 (enero-marzo de 1991).

Epple, Juan Armando. "Introducción". Revista Interamericana de Bibliografía 4 (1996): 9-17.

Escalante Gonzalbo, Fernando. A la sombra de los libros: lectura, mercado y vida pública. México: El Colegio de México, 2007.

Fayad, Luis. "Un personaje en apuros". En La minificción en Colombia. Compilación de Henry González. Bogotá: Universidad Pedagógica Nacional, 2002.

Figueroa, Hugo. "Panorama de la bibliografía". En Recursos bibliográficos y de información. Coordinación de Hugo Figueroa y César Ramírez, 45-62. México: Universidad Nacional Autónoma de México, Facultad de Filosofía y Letras, 2006.

Figueroa, Hugo y Samira García. "Vivencia y convivencia en el universo editorial y de la información". En Recursos bibliográficos y de información. Coordinación de Hugo Figueroa y César Ramírez, 95-139. México: Universidad Nacional Autónoma de México, Facultad de Filosofía y Letras, 2006.

Genette, Gérard. Palimpsestos. Madrid: Taurus, 1989.

Jeannet, Frédéric-Yves. Prólogo a El amor que destruye lo que inventa. Historias de la historia, de Vicente Quirarte, 9-14. México: Consejo Nacional para la Cultura y las Artes, 1995.

Lara Valdez, Josefina. Diccionario bio-bibliográfico de escritores contemporáneos de México. México: Instituto Nacional de Bellas Artes, 1980.

Leal, Luis. Bibliografía del cuento mexicano. México: Ediciones de Andrea, 1958.

"La lectura: una práctica cultural. Debate entre Pierre Bourdieu y Roger Chartier". Traducción de Renán Silva. Revista Sociedad y Economía 4 (2003): 161-175.

Munguía Zatarain, Martha Elena. Elementos de poética histórica: el cuento hispanoamericano. México: El Colegio de México, 2002.

Ocampo, Aurora. Diccionario de escritores mexicanos siglo XX. Desde las generaciones del Ateneo y novelistas de la Revolución hasta nuestros días. 8 tomos. México: Universidad Nacional Autónoma de México, 1988-2005.

Pedroza, Liliana. Historia secreta del cuento mexicano (1910-2017). Monterrey: Universidad Autónoma de Nuevo León, 2018. 
Pereira, Armando. Diccionario de la literatura mexicana. Siglo XX. México: Universidad Nacional Autónoma de México, 2004.

Sabio Pinilla, José Antonio. "¿Es la antología un género? A propósito de las antologías sobre la traducción". Acceso el 7 de octubre de 2019. https:// www.academia.edu/1912731/_Es_la_antolog\%C3\%ADa_un_g\%C3\%A 9nero_A_prop\%C3\%B3sito_de_las_antolog\%C3\%ADas_sobre_la_traduc ci\%C3\%B3n.

Salinas Pérez, Alma Patricia. "Campo literario mexicano: literatura y edición independiente". Tesis de licenciatura. Universidad Nacional Autónoma de México, 2017.

Siruela, Jacobo. "Imaginación, brevedad y memoria". Confabulario. Suplemento de El Universal. Entrevista por J. C. Guinto. Acceso el 9 de octubre de 2019. http://confabulario.eluniversal.com.mx/jacobo-siruela-imaginacion-bre vedad-y-memoria/.

Torres-Rioseco, Arturo. Bibliografía de la novela mejicana. Cambridge: Harvard, 1933.

Torri, Julio. Estudio preliminar a Grandes cuentistas, ix-xix. México: Jackson INC Editores, 1968.

Vital, Alberto. Quince hipótesis sobre géneros. México: Universidad Nacional Autónoma de México, Instituto de Investigaciones Filológicas / Universidad Nacional de Colombia, 2012.

Zavala, Lauro. Paseos por el cuento mexicano contemporáneo. México: Nueva Imagen, 2004. bg 